\title{
LUSTMORD E OS LIMITES DA REPRESENTAÇÃO
}

\section{LUSTMORD AND THE LIMITS OF REPRESENTATION}

Elisa Maia ${ }^{1}$ 


\section{Resumo}

Este artigo aborda o trabalho Lustmord (1993) que a artista visual norte americana Jenny Holzer concebe como uma resposta à violência sexual cometida pelos soldados sérvios contra as mulheres muçulmanas durante a guerra da Bósnia, ocorrida na região dos Bálcãs entre 1992 e 1995, propondo-se a pensar de que maneira o trabalho consegue se impor numa cultura já saturada pelas representações da violência.

Palavras-chave: Jenny Holzer. Representações da violência. Lustmord. Estupro. Cultura visual.

\section{Abstract}

This paper analyses the work Lustmord (1993), by the American visual artist Jenny Holzer, created in response to the atrocious events of sexual violence committed by Serbian soldiers agaist Muslim Women in war-torn Bosnia, from 1992 to 1995. Its objective is to think how Holzers' work managed to assert itself in a culture already saturated with images of violence.

Keywords: Jenny Holzer. Representations of violence. Lustmord. Rape. Visual culture.

ISSN: 2175-2346 


\section{Introdução}

A artista visual norte americana Jenny Holzer, assim como muitos artistas de sua geração que ganharam notoriedade na década de 1980, é produto de um contexto artístico no qual as noções de originalidade e autoria encontram-se sob suspeita. Valendo-se de uma produção fortemente calcada na escrita, Holzer começa sua carreira tomando emprestado livremente ideias, expressões e chavões da cultura de massa para veicular mensagens de conteúdo direto, subversivo e contundente. Embora o texto seja, sem dúvida, o elemento predominante no percurso da artista, na sua obra, as palavras rasgam as fronteiras que lhes são tradicionalmente impostas e investem-se da presença própria da imagem, seduzindo o observador tanto por sua aparência quanto por seu conteúdo provocador. Seu trabalho, portanto, caracteriza-se não apenas por uma dimensão discursiva, como também por uma beleza sensual e pelo uso de efeitos impressionantes que vão do emprego de cor, ritmo, luz e movimento à produção de projeções em escalas monumentais. Neste artigo elegemos um de seus trabalhos, a série Lustmord, de 1993, na qual a metáfora do corpo inscrito ganha sua materialização mais potente, como ocasião para pensar a representação da violência sexual.

\section{Suddeutsche Zeitung}
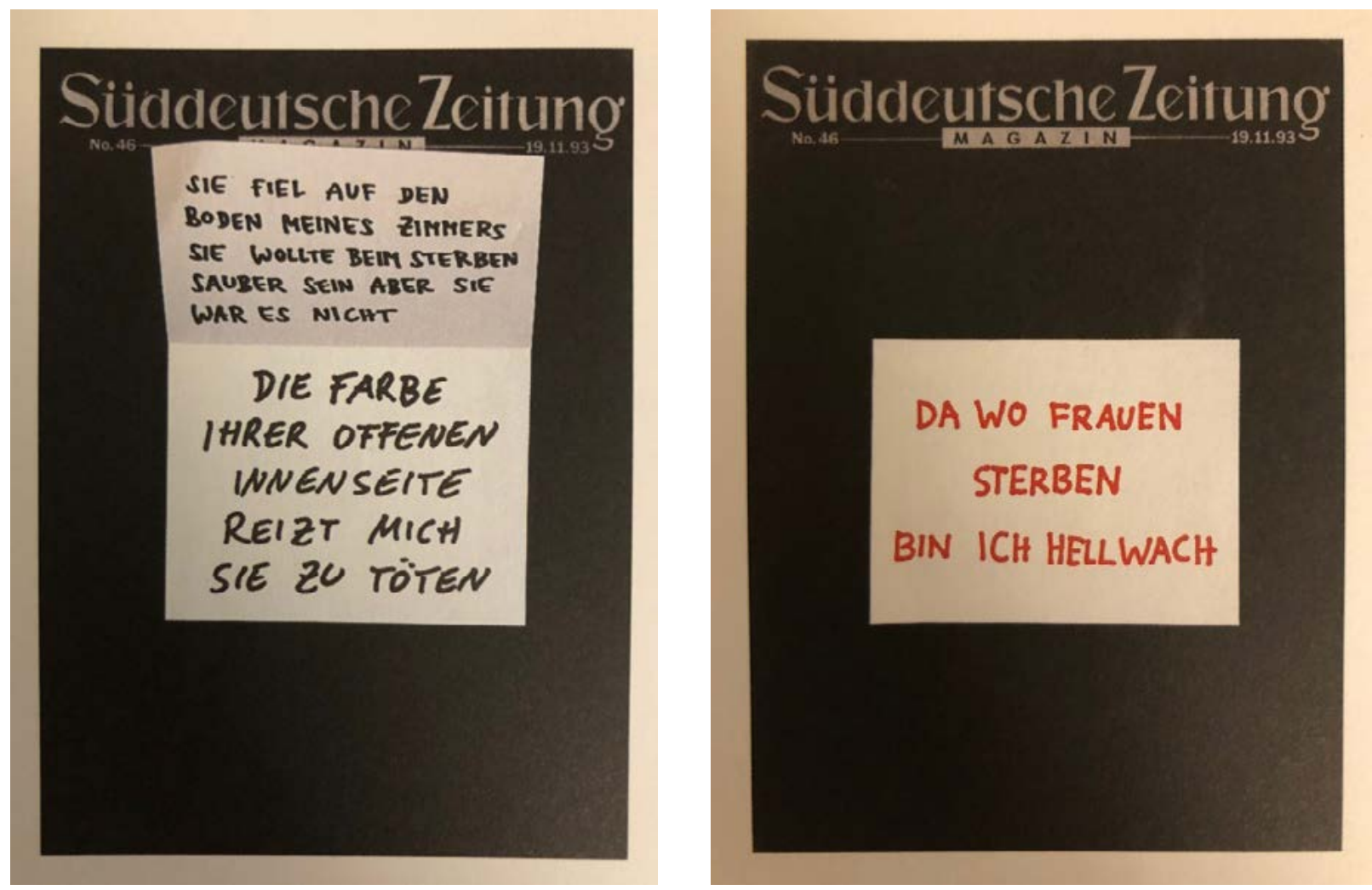

Fig. 1 - Capa da revista Süddeutschen Zeitung. (tinta vermelha feita com sangue humano e tinta preta) N. 46, 11.19.1993. Fonte: Waldman, 1997, p. 114

Em 1992, Jenny Holzer deu início à série Lustmord, concebida em resposta à violência perpetrada às mulheres muçulmanas pelos soldados sérvios durante a guerra da Bósnia, ocorrida na região dos Bálcãs entre 1992 e 1995. A palavra alemã lustmord, 
que não tem correspondentes precisos no inglês ou no português, evoca imagens violentas, traduzidas pela artista como "sex-murder", "rape-slaying" ou "lust-killing", o que, em português, poderia significar algo como "assassinato sexual", ou "estupro seguido de morte". A ideia inicial de Lustmord surgiu a partir de uma encomenda feita pela revista alemã Süddeutsche Zeitung Magazin, o periódico semanal de um jornal de grande circulação em Munique. Lustmord foi a quarta de uma série de parcerias entre a revista e diferentes artistas visuais. O trabalho de Holzer foi publicado na edição de 19 de novembro de 1993, seguindo-se aos trabalhos do alemão Alselm Kiefer, do italiano Francesco Clemente e do norte americano Jeff Koons. O projeto consistia em um suplemento de vinte e oito páginas, inserido no interior da revista, dedicado a fotografias da artista, e mais um cartão de visitas confeccionado separadamente e afixado à capa de cada um de seus 520.000 exemplares (figura 1). A abordagem singular que Lustmord faz do tema do estupro dispensa as fotografias ou os depoimentos que comprovam a "realidade" dos assassinatos sexuais cometidos na Bósnia e, neste sentido, os seus textos podem ser entendidos como ficção. Mas, ainda assim, o trabalho encena um fato histórico conhecido, mas pouco discutido, a saber, o uso do estupro como uma arma e uma estratégia político-militar, levada a cabo sistematicamente por soldados não apenas no conflito específico da Bósnia, mas na maioria das situações de guerra de que se tem notícia. "Na guerra o estupro é normal... faz parte do espólio do soldado, é, por assim dizer, um tipo de pagamento" (WALDMAN, 1997, p. 25), afirmou Holzer sobre o tema. No mesmo sentido, Virginie Despentes (2016), em seu livro Teoria King Kong, coloca:

A vida militar foi até então uma oportunidade de praticar o 'estupro coletivo' por uma boa causa. Tratava-se primeiramente de uma estratégia de guerra, que faz parte da virilização do grupo que o pratica ao mesmo tempo que enfraquece e debilita o grupo adversário (DESPENTES, 2016, p. 30).

Em Lustmord, a experiência traumática de um estupro violento é recriada a partir de textos sucintos que articulam três diferentes perspectivas da experiência: não apenas a do perpetrador da violência e a da vítima, as duas posições mais comuns quando se pensa na experiência de um estupro, mas também a de um observador. Virginie Despentes (2016) enfatiza a nossa obstinação em tornar o estupro algo raro e periférico e, sobretudo, algo evitável, fora da normalidade, que diz respeito apenas a uns poucos agressores e umas poucas vítimas (DESPENTES, 2016, p. 40). Esta terceira pessoa que Lustmord inclui na cena é, portanto, crucial para deslocar o foco que geralmente recai exclusivamente sobre abusador e vítima e iluminar também a forma como o mundo costuma assistir de forma passiva à violência sofrida pelas mulheres.

O perpetrador da violência descreve o corpo violado com desprezo, caracterizando-o como um meio fluido, cujos limites entre interior e exterior foram transgredidos:

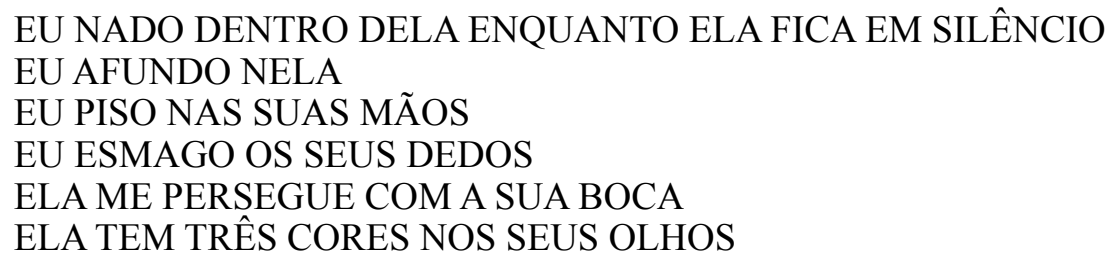


EU A MORDO NOVAMENTE

EU MANDO QUE ELA SE LAVE

SUA SALIVA ESCORRE ENQUANTO ELA DORME

ELA PERDEU SEU REFLEXO DE DEGLUTIÇÃO

ELA CHEIRA A URINA

EU SEGURO A SUA CABEÇA COM SEUS FINOS CABELOS

EU POSICIONO A SUA BOCA

EU QUERO FODÊ-LA ONDE ELA TEM MUITOS PÊLOS

A COR DELA POR DENTRO É SUFICIENTE PARA ME FAZER MATÁ-LA ${ }^{1}$

(WALDMAN, 1997, p. 111, tradução nossa).

A experiência do estupro é reorganizada a partir do relato da vítima, que apesar de ter seu corpo brutalmente invadido, tenta apontar justamente para os limites que o separam do corpo do estuprador:

ESTOU ACORDADA NO LUGAR ONDE AS MULHERES MORREM

VOCÊ ME CONFUNDE COM ALGUMA COISA QUE ESTÁ DENTRO DE VOCÊ

HÁ PÊLOS PRESOS DENTRO DE MIM

MEUS OLHOS ESTÃO ARDENDO PELO CONTATO COM A PALMA DA SUA MÃO

VOCÊ TEM PELE NA SUA BOCA

VOCÊ ME LAMBE ESTUPIDAMENTE

EU TENTO ME EXCITAR ENTÃO FICO MALUCA

EU NÃO GOSTO DE CAMINHAR PORQUE SINTO ISTO ENTRE AS MINHAS PERNAS

EU SEI QUEM VOCÊ É E ISSO NÃO ME FAZ NENHUM BEM

O QUE FICA NA COBERTA É CLARO E TEM A COR DO INFERNO

COM VOCÊ DENTRO DE MIM FICO CIENTE DA MINHA MORTE ${ }^{2}$

(WALDMAN, 1997, p. 112, tradução nossa).

Uma terceira voz registra a cena a partir da perspectiva de um observador, cujo desejo de ajudar é mitigado pelo temor de entrar em contato com o corpo e com os objetos da mulher. Para o observador, a transgressão dos limites do corpo violentado aparece como um motivo de constrangimento para a vítima que se recusa a tornar-se objeto de um olhar voyeurístico:

QUANDO TUDO COMEÇOU A VAZAR DO SEU CORPO ELA CORREU PARA NÃO SER VISTA

EU QUERO ME DEITAR DO LADO DELA

EU VOU FICAR COBERTO DO QUE SAI DE DENTRO DELA

ELA SORRI PARA MIM IMAGINANDO QUE POSSO AJUDÁ-LA

EU QUERO PENTEAR SEU CABELO MAS SEU CHEIRO ME FAZ ATRAVESSAR O QUARTO

EU SEGUREI A RESPIRAÇÃO O MÁXIMO DE TEMPO POSSÍVEL

EU SEI QUE A DESAPONTEI

EU ENCONTRO AS SUAS TOALHAS ENFIADAS EM BURACOS APERTADOS

EU AS LEVO PARA QUEIMÁ-LAS EMBORA EU TENHA MEDO DE TOCAR

$1 \quad$ I swim in her as she quiets / I sink on her / I step on her hands / I splay her fingers / She hunts me with her mouth / She has three colors in her eyes / I bite her closed again / I tell her to soap herself / Her saliva runs when she sleeps / She has a urine smell / Her swallow reflex is gone / I take her face with its fine hairs / I position her mouth / I want to fuck her where she has too much hair / The color of her where she is inside out is enough to make me kill her.

$2 \quad$ I am awake in the place where women die / You confuse me with something that is in you / Hair is stuck inside me / My eyes are sore from moving against your palm / You have skin in your mouth / You lick me stupidly / I try to excite myself so / stay crazy / I do not like to walk because I feel it between my legs / I know who you are and it does me no good at all / What is left on the blanket is clear and the color of hell / With you inside me comes the knowledge of my death. 
NOS SEUS OBJETOS

ELA CAIU NO CHÃO DO MEU QUARTO

ELA TENTOU SER LIMPA QUANDO MORREU MAS NÃO CONSEGUIU

EU VEJO SEU RASTRO ${ }^{3}$

(WALDMAN, 1997, p. 113, tradução nossa).

Para a publicação da revista, essas palavras foram inscritas à mão com tinta preta, vermelha e azul em corpos de homens e mulheres, e fotografadas muito de perto, de forma que poros, pêlos, manchas e sardas aparecessem tão marcados quanto o texto (figura 2). Aqui, como nos outros trabalhos de Holzer, as palavras escritas não ilustram e nem explicam as imagens, elas são a própria imagem, na medida em que são tomadas também como elementos visuais. A materialidade de que se investe o corpo da escrita, bem como a linguagem gráfica, concreta, precisa e substantivada das frases têm um efeito potente, produzem uma fisicalidade que confirma o desejo de Holzer de que seus textos sejam lidos pelos olhos e pelo corpo inteiro. Essa estratégia dialoga com o conceito de uma "erótica da leitura", formulado por em 1966 por Susan Sontag em seu livro Contra a Interpretação, no qual a autora defende uma nova sensibilidade na leitura que desenfatize a construção de sentidos através da razão em benefício da valorização dos aspectos sensuais envolvidos na experiência estética. As frases de Lustmord assemelham-se a fotografias por sua visualidade visceral, pelo modo rápido como são apreendidas e pelo impacto que causam. Além da visibilidade flagrante (são inscritos na pele e fotografados), os textos são criadores de novas visualidades, na medida em que cada espectador produzirá de forma subjetiva uma imagem a partir dos relatos. Há, portanto, a construção de um espaço complexo e singular, resultado da articulação entre as linguagens visual e verbal, que se beneficia de uma ambiguidade entre a sedução e a repulsa. A presença das imagens criadas por Holzer convida o olhar e seduz o espectador, mas, ao ser capturado, esse espectador é compelido a tornar-se leitor, e a construir as suas próprias imagens em diálogo com a realidade repulsiva, quase insuportável, que o texto afirma.

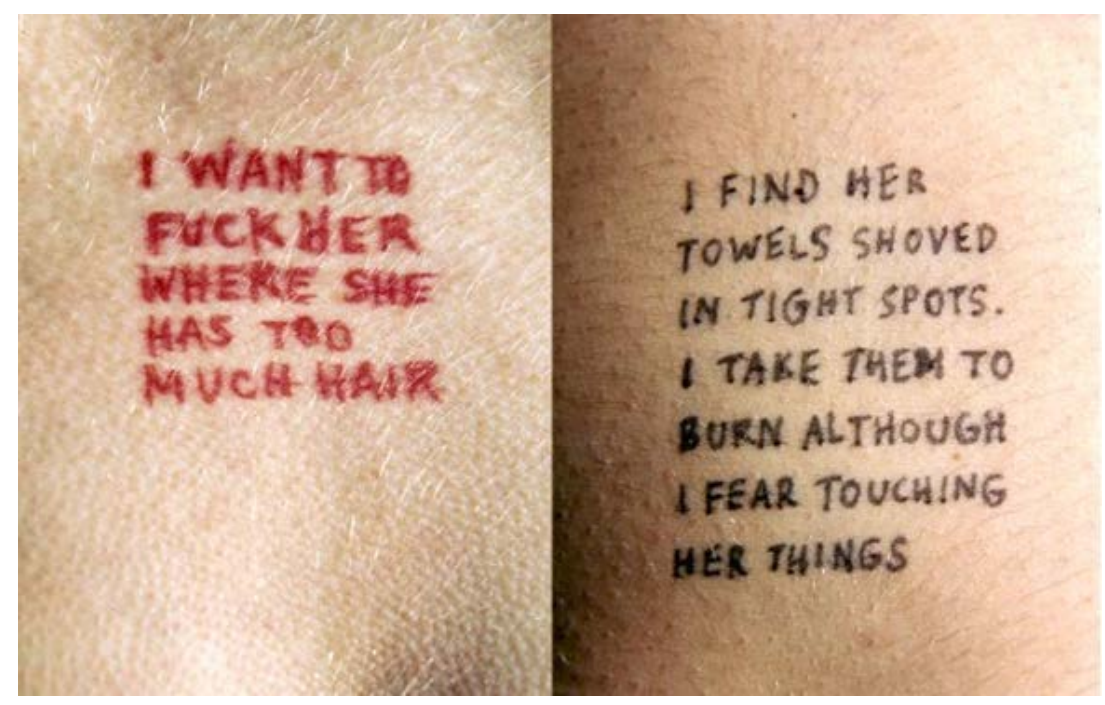

Fig. 2 - Projeto para Süddeutschen Zeitung. N. 46, 11.19.1993. Série Lustmord (1993-1995) Fonte: Joselit, Simon, Salecl, 1998, p. 82.

\footnotetext{
$3 \quad$ She started running when everything began pouring from her because she did not want to be seen / I want to lie down beside her / I will be covered by what has come from her / Ela sorri para mim imaginando que posso ajudá-la / I want to brush her hair but the smell of her makes me cross the room / I held my breath as long as I could / I know I disappointed her / I find her towels shoved in tight spots / I take them to burn although I fear to touch her things / She fell on the floor of my room / She tried to be clean when she died but she was not / I see her trail.
} 
A repercussão causada por Lustmord foi enorme, principalmente considerando o espaço que as obras de arte em geral, e especialmente as obras de arte contemporânea, costumam ocupar na imprensa não especializada. Alguma polêmica já era esperada, uma vez que detalhes mórbidos de uma cena de violência sexual configuram um tema árido e incômodo, mesmo para o leitor acostumado a consumir pelo jornal notícias cada vez mais chocantes. Além disso, Holzer admite que a linguagem usada por ela na série é "pornográfica e precisa" e que esta é uma estratégia deliberada para tornar mais vívida a expressão da violência, da raiva e do desespero envolvidos na experiência do estupro. Por fim, o uso do corpo humano, concebido como suporte para a escrita, contribuía para intensificar este efeito, pois convocava associações com tatuagens e, especialmente na Alemanha, trazia à memória as imagens das marcações nos corpos de prisioneiros dos campos de extermínio nazistas. Mas quando a Süddeutsche Zeitung Magazin chegou à casa dos leitores, em 1993 a Guerra da Bósnia já tinha rendido aos jornais algumas imagens inesquecíveis, como a foto de Ron Haviv tirada na cidade de Bijeljina, que retrata um miliciano sérvio uniformizado no instante em que se prepara para chutar a cabeça de uma mulher muçulmana, morta ou quase, caída sobre a calçada entre dois outros corpos femininos (figura 3). É possivel pensar, portanto, que os leitores da revista já estivessem em certa medida cientes da orgia de violência promovida na Bósnia pelas forças sérvias. Além disso, as relações entre a violência cometida contra as mulheres e as estratégias militares em tempos de guerra já haviam se tornado amplamente conhecidas. Basta lembrar de eufemismos como "joy divisions" - setores dos campos de concentração nos quais mulheres judias serviam de escravas sexuais para soldados e oficiais nazistas, ou "comfort women" - as milhares de mulheres coreanas sequestradas e encarceradas a serviço do exército japonês em bordéis militares na China. Algumas dessas mulheres sobreviveram para contar as suas histórias, e seus testemunhos foram registrados em livros, entrevistas e documentários. Em 1993, as imagens dos prisioneiros bósnios no campo de extermínio criado pelos sérvios em Omarska, no norte da Bósnia, já haviam começado a ser divulgadas, e os jornalistas logo apontaram a ausência quase absoluta de mulheres entre 15 e 35 anos nas fotos.

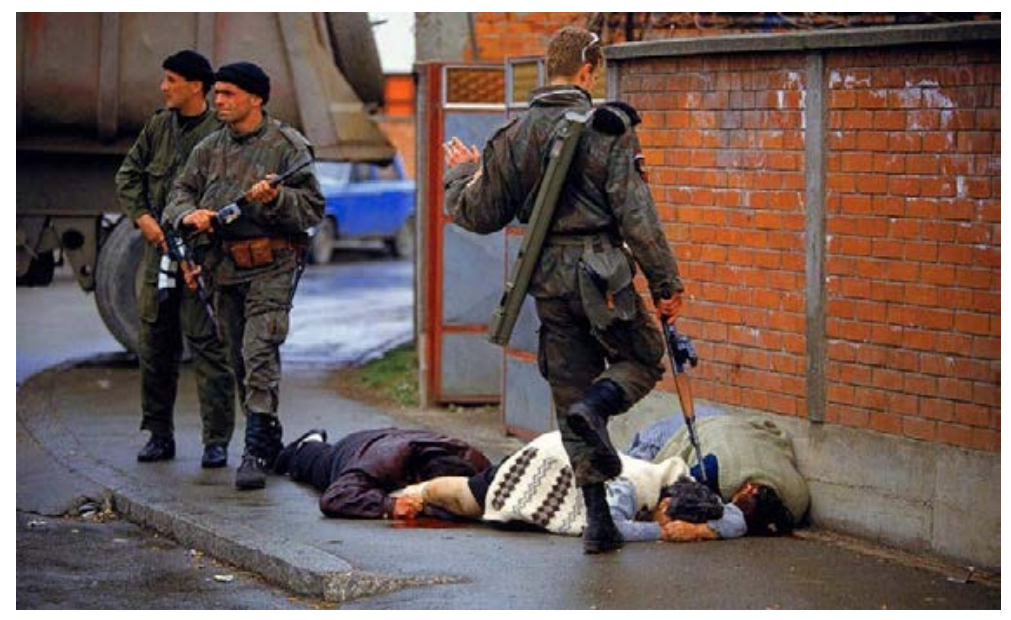

Fig.3 - Foto de Hon Haviv, Bósnia, 1992.

Fonte: <http://100photos.time.com/photos/ron-haviv-bosnia> 
Mesmo assim, a obra causou um escândalo muito maior do que se podia imaginar, tendo sido objeto de debates por dias seguidos em jornais e revistas dentro e fora da Alemanha. Curiosamente, no centro das discussões não estava o conteúdo dos textos (a descrição de certa forma pornográfica da violência sexual cometida contra as mulheres) e nem o eco de memórias traumáticas evocadas pelas marcações dos corpos. O grande alvo dos debates em torno da obra foi a capa da edição, mais especificamente, o material usado para a impressão do seu texto. A parte de dentro do cartão de visita branco afixado à capa da revista trazia duas mensagens. Em tinta preta, lia-se "Die farbe ihrer offenen innenseite reitz mich sie zu toten" (A cor dela por dentro é suficiente para me fazer matá-la) e "sie fiel auf den boden meines zimmers sie wollte beim sterben sauber sein aber sie war es nicht" (Ela tentou ser limpa ao morrer mas não conseguiu. Eu vejo seu rastro). Na parte da frente do cartão lia-se, em vermelho: "Da wo frauen sterben bin ich hellwach" (Estou acordada no lugar onde as mulheres morrem). Mas essas palavras não haviam sido impressas em tinta vermelha apenas como uma maneira de simbolizar o sangue derramado pelas vítimas. Elas foram impressas com sangue de verdade, doado por mulheres alemãs e iugoslavas que se voluntariaram para participar do projeto. Em Lustmord, portanto, há um resgate da origem corporal da palavra, que se faz presente não apenas porque os textos são escritos à mão, o que enfatiza a escrita como gesto corporal, como também, porque tanto o suporte (pele), quanto a tinta (sangue) derivam do corpo humano. O sangue doado pelas voluntárias passou por um procedimento rigoroso antes de ser misturado à tinta de impressão usada nos cartões, sendo submetido a testes de hepatite e HIV e, então, superaquecido para eliminar a presença de agentes infecciosos. Ainda assim, o gesto foi responsável por uma verdadeira comoção e Holzer foi acusada de uma série de contravenções - desde agitação política até desperdício de sangue. A julgar pela capa da revista, o leitor esperava encontrar nas fotografias inseridas no interior da edição imagens que ilustrassem a violência evocada pelo texto. Contudo, essas expectativas são frustradas, uma vez que elas não traziam nenhuma imagem gráfica da situação apresentada na capa. O desejo da vítima de Lustmord, que corre "para não ser vista", é respeitado pela ausência de imagens gráficas do corpo violado. Nas fotografias, a figura do corpo humano é reduzida a uma região pequena e não identificável e sequer é possível saber se se trata de um corpo feminino ou masculino. O espaço onde se espera ver imagens (retratos da vítima, do perpetrador, do local onde foi cometida a violência) é povoado por palavras, ao passo que essas mesmas palavras são repletas de possíveis imagens.

Considerou-se que a presença do sangue na casa dos mais de quinhentos mil leitores do suplemento semanal de um jornal popular, ainda que testado em laboratório, livre de germes, e em quantidades ínfimas, extrapolava um limite ético. 0 projeto foi discutido em diferentes publicações, atraindo tanto respeito - o trabalho recebeu a medalha de ouro do Clube de Diretores de Arte da Alemanha em 1994 -, quanto críticas severas, de setores que o consideraram muito visceral, muito literal, mas, sobretudo, uma ameaça à saúde daqueles que manusearam o cartão. Um tribunal regional da Alemanha chegou a sugerir o recolhimento da edição sob a acusação de que a revista constituiria uma "ameaça à saúde pública" (Simon, 1994, p. 82). No centro das preocupações estava o medo da transmissão de doenças, em 
geral, e do vírus HIV, em especial. A revista Time US de 29 de novembro de 1993, num artigo intitulado Talk of the Streets afirmou que a Süddeutsche Zeitung Magazin havia tentado levar a violência perpetrada às mulheres na guerra diretamente para a casa de 520.000 leitores e que esta iniciativa havia sido considerada por muitos sensacionalista demais. Peter Heimer, conselheiro da Cruz Vermelha alemã, foi além num pronunciamento no qual afirmou que o ato era "repulsivo e absurdo" (SIMON, 1994 , p. 82). Somado ao temor diante do suposto risco de contaminação, muitos leitores experimentavam a sensação de terem sido enganados, uma vez que só era possivel saber da presença do sangue no cartão afixado à capa, a partir da leitura do interior da revista, ou seja, após já tê-lo manuseado. Não era a crueza das palavras e nem a realidade que elas denunciavam as responsáveis pelas reações suscitadas, mas sim, o fato de o leitor, desavisado, ter entrado em contato com os resquícios do sangue de uma desconhecida. A forma como eles reagiam à notícia de que o cartão continha sangue feminino ecoava a posição do observador de Lustmord, que teme "tocar nos objetos" que tiveram contato com a vítima da violência.

A repercussão causada pelo projeto expõe questões polêmicas como o medo que se tem de sangue em geral e, especialmente, do sangue feminino, e as noções de sangue impuro, ou contaminado, noções centrais às próprias práticas de limpeza étnica empreendidas pelos soldados sérvios. Além disso, o gesto pode ser interpretado como uma acusação da responsabilidade ou da culpa das quais o espectador prefere se imaginar isento. Neste sentido, é como se o trabalho sugerisse que aqueles que consomem de forma passiva, distante e segura as imagens da guerra também tivessem "sangue nas mãos". Mas, ainda assim, é no mínimo estranho pensar que uma única frase impressa com algumas gotas de sangue doado por mulheres voluntárias possa chocar mais do que a enorme quantidade de sangue derramada pelas milhares de mulheres inocentes, tornadas vítimas de conflitos civis e políticos. $O$ episódio coloca, então, uma série de questões, dentre as quais, vale destacar a seguinte: de que forma a estratégia usada por Holzer para abordar a violência cometida contra as mulheres na guerra pode ser mais "chocante", mais "repulsiva" e mais "absurda" não só do que a própria realidade a que a obra se refere, mas também do que a outras incontáveis representações (muitas delas mais explícitas) dessa mesma realidade? Em outras palavras, como o trabalho de Holzer consegue se impor numa cultura já saturada pela violência e pelas representações da violência?

Um caminho possivel seria afirmar que o trabalho constituiu uma ameaça não tanto à saúde do espectador/leitor, mas sobretudo ao sistema de representação em que se insere a imagem/texto. A materialidade de que se investe o corpo da escrita (sangue feminino) desestabiliza o sistema pelo qual estamos acostumados a consumir as imagens que representam um "objeto real". Em Lustmord, o objeto (sangue) é convertido em texto e o texto, por sua vez, é convertido em imagem. Imagem e objeto, então, se confundem, e ambos são tocados não apenas pelo olhar, mas pelas próprias mãos do espectador. Holzer faz com que a imagem, que nos acostumamos a pensar como o substituto de uma realidade ausente, torne presente resquícios dessa própria realidade, que até aceitamos assistir, desde que de uma distância segura. A distância entre o sujeito que olha, a imagem que representa e o objeto representado é, assim, suprimida, e a falsa proximidade criada pelos meios de comunicação - entre 
o espectador que acompanha a guerra de sua poltrona e a vítima das atrocidades noticiadas - é convertida em uma proximidade real. Neste sentido, a combinação estratégica que Holzer faz de sangue e tinta, corpo e palavra, promoveria uma reconfiguração do espaço da representação, alterando a lógica usual do consumo dessas imagens, lógica que obedece a uma hierarquia entre o sujeito que observa e o objeto da observação.

\section{Considerações Finais}

A decisão de abordar um tema como a violência sexual coloca o artista numa posição delicada, uma vez que a linha que separa a apresentação de um sofrimento com fins de intervir na realidade que o comporta e a exploração de um sofrimento com fins comerciais é tênue e instável. Em entrevista para a própria Suddeutsche Zeitung Magazin, Jenny Holzer aponta o risco que as representações realistas correm de serem utilizadas como uma forma de pornografia e, portanto, como uma segunda violência contra as vítimas. A artista cita como um dos exemplos mais perversos um material de cunho documental sobre os crimes da antiga lugoslávia que passou a ser vendido como vídeo pornográfico por preços cada vez mais altos. A dor é uma experiência singular e privada e que o sujeito sofre muitas vezes sente-se isolado pela suposta incomunicabilidade de sua experiência. Mas talvez seja necessário buscar formas de tentar ultrapassar as barreiras que definem essas experiências como incomunicáveis, encontrando um equilíbrio entre o completo isolamento e a exploração inescrupulosa, entre o silêncio (ou a negação) e a exposição pornográfica. $O$ uso da violência sexual como uma arma e uma estratégia político-militar, levada a cabo sistematicamente por soldados em regiões devastadas por conflitos civis e políticos não é desconhecido, mas talvez seja pouco discutido. É importante que situações como a ocorrida na Bósnia na década de 1990, na Síria atualmente e tantas outras que transcorrem relativamente isentas de documentação sejam não apenas conhecidas, mas que se reflita sobre elas a partir de uma perspectiva distinta, ampliando-se o já exaurido foco que enquadra apenas a vítima e o seu sofrimento e na pior das hipóteses avalia até mesmo sua suposta culpabilidade. Virginie Despentes (2016) conta que após ter sido estuprada junto com uma amiga por três homens que lhes ofereceram carona, passou a vida inteira sendo questionada pelas pessoas sobre o porquê de depois disso ela continuar aceitando carona de estranhos, como se esse fosse um indício da sua anuência, "porque num estupro você sempre precisa provar que não estava de acordo" (Despentes, 2016, p. 37). No centro da orquestra de vozes articulada em Lustmord não está a mulher, mas sim a própria experiência do estupro e a relação que se estabelece entre esses três sujeitos, apresentados não como objeto da fala de um terceiro, mas como sujeitos de um discurso próprio, ainda que fictício. A figura do "observador" ou da "testemunha" que divide o espaço da obra com o "perpetrador" e a "vítima" ressalta que o outro, objeto do olhar, é também alguém que olha. Além das três posições criadas por Holzer, o trabalho inclui uma quarta, a do observador privilegiado, leitor da revista, cuja distância confortável da vítima é forçosa e inesperadamente suprimida. Lustmord parece afirmar que apenas olhar não é suficiente, é necessário também dar-se conta de que se está olhando, refletir sobre 
o que significa testemunhar. Neste sentido, o espectador é convidado não apenas a se confrontar com a realidade brutal afirmada pelo trabalho, mas também com o significado e as implicações de ser espectador desta realidade. Seu mérito, portanto, não está tanto na sua capacidade de conscientizar os leitores da Süddeutsche Zeitung Magazin sobre as atrocidades cometidas na Bósnia e nem de causar a sua indignação, embora isso deva ocorrer também. Trata-se de estabelecer novas maneiras de afirmar uma realidade que, em maior ou menor grau, já era conhecida e, sobretudo, de lançar novos olhares para esta realidade, incluindo outros agentes que a constituem, e estabelecendo novas configurações nas relações entre a dor e o sofrimento individual de quem sofre a responsabilidade coletiva dos que assistem passivamente. $O$ trabalho de Holzer explora o poder da linguagem de uma maneira complexa, multivalente, na qual os domínios do conteúdo e da forma, dos significados e dos afetos, do inteligível e do sensível se amplificam e se confundem. Coloca-se ao lado das iniciativas que se recusam a conceber a arte como um objeto distante, intocável, aquém ou além da política e das questões sociais, econômicas e culturais que atravessam o cotidiano dos indivíduos. Afirma que a arte deve ser "tocada", discutida, elaborada, provocando afetos e efeitos sensuais ao mesmo tempo em que gera reflexão e não para de propor questões. Neste sentido, coincide com o que Mieke Bal (2007) chamou de uma filosofia visual, referindo-se a imagens que levantam questões sem, no entanto, respondê-las (REINDHART, EDWARDS, DUGANNE, 2007).

\section{Referências}

BAL, Mieke. Reading Rembrandt: beyond the word-image opposition. Amsterdam: Amsterdam University Press, 2006.

The Pain of Images. In: REINHARDT, Mark; EDWARDS, Holly; DUGANNE, Erina. Beautiful Suffering: Photography and Traffic in Pain. Chicago: University of Chicago Press, 2007.

DESPENTES, Virginie. Teoria King Kong. Tradução Márcia Bechara. São Paulo: n-1 edições, 2016.

FERGUNSON, Bruce. Wordsmith: an interview with Jenny Holzer. Art in America, p. 109-113, dez. 1986.

FOSTER, Hal. Subversive sign. In: Recording: art, spectacle, cultural politics. Seattle: Bay Press, 1986, p. 88-91.

HUGHES, Gordon. Power's Script: or, Jenny Holzer's Art after 'Art after Philosophy' Oxford Art Journal, Volume 29, Issue 3, 1 October 2006, Pages 419-440, 01 October 2006.

JOSELIT, David; SIMON, Joan; SALECL, Renata. Jenny Holzer. London: Phaidon Press, 1998. 
MADOFF, Steven H. Jenny Holzer talks to Steven Henry Madoff. Artforum International, 41.8, p. 82-83, 2003.

REINHARDT, Mark; EDWARDS, Holly; DUGANNE, Erina. Beautiful Suffering: Photography and Traffic in Pain. Chicago: University of Chicago Press, 2007.

SONTAG, Susan. Diante da dor dos outros. Tradução Rubens Figueiredo. São Paulo: Companhia das Letras, 2003.

WALDMAN, Diane. Jenny Holzer. Nova lorque: Guggenheim Museum, 1997. 